\title{
POTENCIAL DE GENÓTIPOS DE TRIGO DURO PARA PRODUTIVIDADE E CARACTERES AGRONÔMICOS NO ESTADO DE SÃO PAULO (1)
}

\author{
ALLAN HENRIQUE DA SILVA $\left(\left(^{*}\right)\right.$; CARLOS EDUARDO DE OLIVEIRA CAMARGO $\left({ }^{3}\right)$; \\ EDISON ULISSES RAMOS JÚNIOR $\left(^{4}\right)$
}

\begin{abstract}
RESUMO
O trigo duro produz a semolina que, extraída dos grãos, é a matéria-prima empregada na elaboração de macarrão. Assim, o objetivo deste estudo foi avaliar o potencial produtivo e comportamento agronômico de 17 linhagens de trigo duro (BH-1146/LGN//2*IAC-1003) oriundas do programa de melhoramento do Instituto Agronômico (IAC) e três cultivares-controle: IAC-1001, IAC-1002 e IAC-1003, originárias de introduções do Centro Internacional de Melhoramento de Milho e Trigo (CIMMYT), México. Os experimentos foram instalados em Capão Bonito (sequeiro) e em Mococa (irrigado), em 2007 e 2008. Foram avaliados os seguintes caracteres: produtividade $\left(\mathrm{kg} \mathrm{ha}^{-1}\right)$, altura das plantas, comprimento da espiga e comprimento do internódio da raque (cm), número de grãos por espiga e massa de cem grãos $(\mathrm{g})$. A tolerância à toxicidade de alumínio foi realizada empregando soluções nutritivas, no laboratório. As cultivares IAC-1001 e IAC-1003 destacaram-se quanto à produção de grãos nos dois locais. As linhagens 2, 9 e 13 possuem porte semianão mais baixo; as linhagens 4, 15 e a cultivar IAC-1001 exibiram espigas mais compridas; as cultivares IAC-1001 e IAC-1002 sobressaíram-se pelo grande número de grãos por espiga; a 'IAC-1003' pelos grãos mais pesados e as linhagens 1, 4, 15 e 17 revelaram maior comprimento do internódio da raque. Houve tendência dos genótipos de porte semianão mais alto serem mais produtivos, com maior número de grãos por espiga e grãos mais pesados. As linhagens obtidas pelo programa de melhoramento do IAC foram tolerantes à toxicidade de alumínio e as cultivares-controle sensíveis.
\end{abstract}

Palavras-chave: triticum durum L., melhoramento de plantas, tolerância ao alumínio.

\section{ABSTRACT \\ POTENTIAL OF DURUM WHEAT GENOTYPES FOR PRODUCTIVITY AND AGRONOMIC TRAITS IN SÃO PAULO STATE}

Semolina extracted from grains of durum wheat is used for manufacturing pastas. Therefore, it is of interest to evaluate the yield potential and agronomic behavior of seventeen durum wheat inbred lines (BH-1146/ LGN / /2*IAC-1003) originated from Instituto Agronômico (IAC) breeding program and three check cultivars IAC1001, IAC-1002 and IAC-1003, introduced from International Maize and Wheat Improvement Center (CIMMYT), Mexico. The experiments were carried out in upland conditions at Capão Bonito and under irrigation at Mococa, in 2007 and 2008. The following characters were evaluated: yield $\left(\mathrm{kg} \mathrm{ha}^{-1}\right)$, plant height, head length and raquis internode length $(\mathrm{cm})$, number of grains per spike and 100 grains weight $(\mathrm{g})$. The tolerance to aluminum toxicity was evaluated in nutrient solution, under laboratory conditions. 'IAC-1001' and 'IAC-1003' showed good performance in relation to grain yield at the two locations. The inbred lines 2, 9 and 13 showed shorter semi dwarf plant type; inbred lines 4, 15 and the cultivar IAC-1001 had longer heads; 'IAC-1001' and 'IAC-1002' exhibited more fertile spikes; 'IAC-1003' heavier grains and the inbred lines 1, 4, 15 and 17 presented higher raquis internode length. The more productive genotypes tent to present taller semi dwarf plant types, more of grain per spike and heavier grains. The inbred lines from the IAC breeding program were tolerant to aluminum toxicity and the check cultivars were sensitive.

Key words: Triticum durum L., plant breading, aluminum tolerance.

(1) Parte da dissertação apresentada ao Curso de Pós-graduação em Agricultura Tropical e Subtropical do Instituto Agronômico (IAC). Recebido para publicação em 3 de fevereiro de 2009 e aceito em 2 de março de 2010.

(2) Instituto Agronômico, Caixa Postal 28, 13012-970 Campinas (SP). Bolsista de mestrado da FAPESP. E-mail: allanhenrique_agron@yahoo. com.br. $\left(^{*}\right)$ Autor correspondente.

(3) In memoriam.

$\left(^{4}\right)$ Polo Regional do Desenvolvimento Tecnológico dos Agronegócios do Sudoeste Paulista, Caixa Postal 62, 18300-970 Capão Bonito (SP). 


\section{INTRODUÇÃO}

O trigo duro, pertencente à espécie Triticum durum L., cuja farinha é utilizada para a elaboração de massas alimentícias (macarrão), é um cereal cultivado em aproximadamente 17 milhões de hectares no mundo, com produção de 25 milhões de toneladas e produtividade média de $1.500 \mathrm{~kg} \mathrm{ha}^{-1}$. O Canadá, União Européia, Noroeste da África e os Estados Unidos são os maiores produtores e exportadores de trigo duro (UsDA, 2008).

As massas alimentícias secas, no Brasil, são produzidas, em quase sua totalidade, a partir de farinha de trigo comum (Triticum aestivum L.). No entanto, as massas elaboradas a partir da sêmola, originária do trigo duro totalmente importado, representam 3\% do volume total comercializado (AвIMA, 2008).

Para atender a demanda da indústria de pastas alimentícias por semolina, pesquisas com trigo duro foram iniciadas em 1984 no Instituto Agronômico (IAC). Foram feitas seleções de genótipos com caracteres agronômicos superiores e boas qualidades tecnológicas, em solo corrigido e irrigado (CAMARGO et al., 1995b).

Entretanto, os genótipos de trigo duro disponíveis para cultivo no país, particularmente no Estado de São Paulo, não tiveram muito sucesso devido a problemas agronômicos. Proporcionaram baixa produtividade em solos ácidos, devido à elevada sensibilidade ao alumínio (CAMARGO et al., 1992), suscetibilidade às doenças foliares e ausência de dormência dos grãos (CAMARGo e FERrEIRA FILHO, 2000). Além da dificuldade de comercialização do grão, o Brasil é um grande importador desse cereal.

O desenvolvimento de novas cultivares de trigo duro tolerantes ao alumínio, para cultivo em condição de sequeiro e solos ácidos, tem sido de grande interesse, pois o Brasil possui grandes áreas de cerrado, que representam cerca de $25 \%$ da área nacional, caracterizado por exibir elevados níveis de alumínio trocável no solo (CAMARGO, 1993). A obtenção de genótipos com potencial produtivo para cultivo de sequeiro tem sido de suma importância, tendo em vista que a triticultura nacional se instala em sua maioria nessas condições (CAMARGO e FERREIRA FILHO, 2000).

Genótipos de trigo duro com alto potencial de produção de grãos, em cultivo com irrigação por aspersão e solo corrigido, foram identificados por Felício et al. (1999 e 2005) e CAMARGo et al. (1993; 1995a). Esses autores demonstraram que nessas condições os melhores genótipos de trigo duro não diferiram das cultivares de trigo comum utilizadas como controle.

Avaliando linhagens de trigo duro, CAMARGo et al. (1995b) identificaram genótipos superiores quanto à produção de grãos, comprimento da espiga, número de grãos por espiga e massa de cem grãos, em experimentos desenvolvidos em condição de irrigação.

Como a produção de grãos é um caráter complexo e altamente influenciado pelo ambiente, a seleção por meio de seus componentes pode ser mais efetiva, por utilizar controle genético mais simples (Medeiros e SCHLEHUBER, 1971). A associação entre a produção e outros caracteres tem sido estimada, visando identificar a inter-relação e seus efeitos entre esses caracteres em genótipos de trigo duro (GEBEYEHOU et al., 1982; ElHANI, et al., 2007;) e em trigo comum (BIUdEs et al., 2007; LOBATO et al., 2005).

O objetivo deste trabalho foi avaliar o potencial de genótipos de trigo duro quanto à produção de grãos e outros caracteres agronômicos e estimar as associações entre a produção e os demais caracteres estudados, além de avaliar os genótipos quanto à toxicidade do alumínio em solução nutritiva.

\section{MATERIAL E MÉTODOS}

Foi avaliado o comportamento agronômico de 20 genótipos de trigo duro, sendo 17 linhagens obtidas pelo programa de melhoramento do Instituto Agronômico (IAC) e trêscultivares-controleIAC-1001,IAC-1002eIAC1003, originárias de introduções do Centro Internacional de Melhoramento de Milho e Trigo (CIMMYT), México. As 17 linhagens foram obtidas por seleção de populações híbridas provenientes do cruzamento entre a cultivar de trigo comum $\mathrm{BH}-1146$, tolerante à toxicidade de alumínio e a linhagem aneuplóide, de trigo duro, tipo de inverno, Langdon, obtida na Universidade de Norte Dakota, muito sensível à toxicidade de alumínio seguido de dois retrocruzamentos para a cultivar IAC-1003 (BH1146/LGN / / 2*IAC-1003).

Os experimentos foram instalados em Capão Bonito $\left(24^{\circ} 02^{\prime} \mathrm{S}, 48^{\circ} 22^{\prime} \mathrm{W}\right.$, altitude de $\left.702 \mathrm{~m}\right)$, pertencente à zona tritícola $\mathrm{B}$, em condições de sequeiro e em Mococa $\left(21^{\circ} 28^{\prime} \mathrm{S}, 47^{\circ} 01^{\prime} \mathrm{W}\right.$, altitude de $\left.665 \mathrm{~m}\right)$, pertencente à zona tritícola $\mathrm{H}$, em condições de irrigação por aspersão, em solos corrigidos com aplicação de calcário, em 2007 e 2008 .

O delineamento experimental utilizado foi o de blocos ao acaso com quatro repetições, totalizando 80 parcelas. Em Capão Bonito, a semeadura foi manual, sendo as parcelas constituídas por seis linhas de $3 \mathrm{~m}$ de comprimento, espaçadas $0,2 \mathrm{~m}$ entre linhas e $0,6 \mathrm{~m}$ entre parcelas. Em Mococa, utilizou-se semeadura mecânica, as parcelas foram constituídas por oito linhas de $3 \mathrm{~m}$ de comprimento, espaçadas $0,17 \mathrm{~m}$ entre linhas e $0,6 \mathrm{~m}$ entre parcelas. A densidade de semeadura empregada nos experimentos foi equivalente a 1.440 sementes por parcela em uma área útil de colheita de 3,6 m². 
Em Capão Bonito, em 2007 e 2008, foram realizadas sucessivas aplicações (a cada quinze dias após a germinação) com o fungicida Nativo, para o controle de doenças, devido à grande suscetibilidade da espécie trigo duro a essas doenças e a ocorrência de alta quantidade de inóculo de fungos, causadores principalmente de manchas foliares neste local (INSTITUTO Agronômico, 2002). Portanto, nos ensaios de Capão Bonito objetivou-se avaliar os genótipos nas condições de solo e clima, minimizando a ocorrência de doenças.

Avaliaram-se, em cada ano e local, os seguintes caracteres:

Produtividade: considerando a produção total de grãos, em gramas, obtidas nas seis ou oito linhas de cada parcela, transformada em $\mathrm{kg} \mathrm{ha}^{-1}$.

Altura das plantas: compreendendo a distância em centímetro, do nível do solo ao ápice da espiga, excluindo-se as aristas.

Comprimento da espiga: considerando o comprimento médio das espigas, em centímetros, excluindo-se as aristas.

Número de grãos por espiga: considerando o número médio de grãos contados nas espigas.

Massa de cem grãos: levando em consideração a massa, em gramas, do número total de grãos das espigas, o qual foi transformado para massa de cem grãos.

Comprimento do internódio da raque: efetuando a divisão entre o comprimento médio da espiga e o número médio de espiguetas por espiga.

Para cada caráter avaliado, efetuou-se uma análise de variância individual, visando detectar efeitos de genótipos e repetições, e uma análise conjunta, por local, considerando os dois anos de cultivo. Nas análises de variância conjuntas, utilizaram-se como estimativas do desvio-padrão residual para os efeitos de genótipos e de anos o quadrado médio da interação genótipos $x$ anos e para o efeito da interação o quadrado médio do resíduo. O teste de Tukey, a 5\% de probabilidade, foi utilizado para comparar as médias dos genótipos para cada um dos caracteres avaliados.

Foram utilizadas as médias nos dois anos dos caracteres avaliados das 80 parcelas em cada local, para estimar as correlações simples com a produção de grãos.

Para avaliação da tolerância à toxicidade de alumínio $\left(\mathrm{Al}^{3+}\right)$, nas plântulas dos 20 genótipos de trigo duro mais as cultivares-controle de trigo comum: $\mathrm{BH}-$ 1146 (tolerante) e Anahuac (sensível), foram utilizadas soluções nutritivas em condição de laboratório, nas doses de 0, 1, 2, 3, 4 e 6 mg. $\mathrm{L}^{-1}$ de $\mathrm{Al}^{3+}$. Adotou-se o método estabelecido por CAMARGO et al. (2006). Neste caso, o delineamento experimental utilizado foi em blocos ao acaso, com quatro repetições, dispostos em parcelas subdivididas: as parcelas, compostas de seis concentrações de alumínio, e as subparcelas, de genótipos de trigo duro. $\mathrm{Na}$ análise dos dados, considerou-se a média do comprimento da raiz primária central das cinco plantas de cada genótipo, para cada repetição. Os genótipos com crescimento radicular foram considerados tolerantes; aqueles sem crescimento das raízes foram considerados sensíveis, depois de 72 horas em solução nutritiva completa sem alumínio, que se seguiu a 48 horas de crescimento nas soluções contendo seis diferentes concentrações de alumínio.

\section{RESULTADOS E DISCUSSÃO}

As análises de variância (individuais e conjuntas) para produção de grãos dos genótipos avaliados em Capão Bonito, em condição de sequeiro e em Mococa, em condição de irrigação por aspersão, em 2007 e 2008, estão apresentadas na tabela 1. Os quadrados médios da análise de variância conjunta para os ensaios de Capão Bonito não revelaram significância para genótipos, porém houve efeitos significativos para anos e interação genótipos $\mathrm{x}$ anos. Esses resultados concordaram com os obtidos por Felício et al. (2004), avaliando linhagens de trigo comum, em Capão Bonito, que também demonstraram grande influência dos anos no desempenho dos genótipos nessa condição de sequeiro.

Em Capão Bonito, em 2007, a produção de grãos variou de 1.208 a $3.422 \mathrm{~kg} \mathrm{ha}^{-1}$, e cultivares IAC-1001 e IAC-1003, oriundas do CIMMYT, México, destacaramse com a produção de 3.391 e $3.422 \mathrm{~kg} \mathrm{ha}^{-1}$, diferindo das demais linhagens avaliadas no experimento.

Em 2008, ano influenciado por fatores adversos, tais como estresse hídrico após o florescimento, revelou produtividade menor do que em 2007, variando de 826 a $1.677 \mathrm{~kg} \mathrm{ha}^{-1}$. A cultivar IAC-1001 exibiu maior produção $\left(1.677 \mathrm{~kg} \mathrm{ha}^{-1}\right)$, diferindo apenas das linhagens 1 e 13, com produção, respectivamente, de 1.052 e $826 \mathrm{~kg} \mathrm{ha}^{-1}$. Pode-se destacar que em várias linhagens oriundas do programa de melhoramento de trigo duro do IAC, não houve produtividade menor que da cultivar IAC-1001, a mais produtiva.

Os resultados da análise conjunta para produção de grãos dos ensaios instalados em Mococa revelaram efeitos significativos para genótipos e anos. Devido à ausência de interação genótipos x anos nesse local, os genótipos foram avaliados considerando a média nos dois anos de cultivo. Em ensaios de linhagens de trigo duro instalados em Mococa, CAMARGo et al. (1995b) também verificou pouca influência dos anos no desenvolvimento dos genótipos quanto à produção 
Tabela 1. Produtividade média dos vinte genótipos de trigo duro avaliados em condições de sequeiro (Capão Bonito) e com irrigação por aspersão (Mococa), em 2007 e 2008

\begin{tabular}{|c|c|c|c|c|c|c|}
\hline \multirow{2}{*}{ Genótipos } & \multicolumn{3}{|c|}{ Capão Bonito } & \multicolumn{3}{|c|}{ Mococa } \\
\hline & 2007 & 2008 & Média & 2007 & 2008 & Média \\
\hline & & & & & & \\
\hline 1 & $1.318 \mathrm{~d}$ & $1.052 \mathrm{bc}$ & 1.185 & 5.750 & 5.035 & $5.392 \mathrm{a}-\mathrm{c}$ \\
\hline 2 & $1.672 \mathrm{~cd}$ & $1.229 \mathrm{a}-\mathrm{c}$ & 1.451 & 6.089 & 4.962 & $5.525 \mathrm{a}-\mathrm{c}$ \\
\hline 3 & $2.089 \mathrm{bc}$ & $1.292 \mathrm{a}-\mathrm{c}$ & 1.690 & 5.990 & 5.222 & $5.606 \mathrm{a}-\mathrm{c}$ \\
\hline 4 & $1.813 \mathrm{~cd}$ & $1.323 \mathrm{a}-\mathrm{c}$ & 1.568 & 6.120 & 5.101 & $5.610 \mathrm{a}-\mathrm{c}$ \\
\hline 5 & $2.130 \mathrm{bc}$ & $1.483 \mathrm{ab}$ & 1.806 & 5.646 & 4.965 & $5.306 \mathrm{bc}$ \\
\hline 6 & $1.797 \mathrm{~cd}$ & $1.451 \mathrm{ab}$ & 1.624 & 5.729 & 5.208 & $5.469 \mathrm{a}-\mathrm{c}$ \\
\hline 7 & $1.531 \mathrm{~cd}$ & $1.531 \mathrm{ab}$ & 1.531 & 5.563 & 5.125 & $5.344 \mathrm{bc}$ \\
\hline 8 & $1.698 \mathrm{~cd}$ & $1.403 \mathrm{a}-\mathrm{c}$ & 1.550 & 5.672 & 5.330 & $5.501 \mathrm{a}-\mathrm{c}$ \\
\hline 9 & $1.807 \mathrm{~cd}$ & $1.281 \mathrm{a}-\mathrm{c}$ & 1.544 & 5.760 & 5.267 & $5.514 \mathrm{a}-\mathrm{c}$ \\
\hline 10 & $1.609 \mathrm{~cd}$ & $1.212 \mathrm{a}-\mathrm{c}$ & 1.411 & 5.063 & 4.615 & $4.839 \mathrm{c}$ \\
\hline 11 & $1.208 \mathrm{~d}$ & $1.302 \mathrm{a}-\mathrm{c}$ & 1.255 & 5.339 & 5.063 & $5.201 \mathrm{bc}$ \\
\hline 12 & $1.776 \mathrm{~cd}$ & $1.448 \mathrm{ab}$ & 1.612 & 5.464 & 5.240 & $5.352 \mathrm{bc}$ \\
\hline 13 & $1.714 \mathrm{~cd}$ & $826 c$ & 1.270 & 5.703 & 4.854 & $5.279 \mathrm{bc}$ \\
\hline 14 & $1.698 \mathrm{~cd}$ & $1.396 \mathrm{a}-\mathrm{c}$ & 1.547 & 5.427 & 4.948 & $5.188 \mathrm{bc}$ \\
\hline 15 & $1.474 \mathrm{~cd}$ & $1.267 \mathrm{a}-\mathrm{c}$ & 1.371 & 5.287 & 4.330 & $4.808 \mathrm{c}$ \\
\hline 16 & $1.589 \mathrm{~cd}$ & $1.382 \mathrm{a}-\mathrm{c}$ & 1.485 & 5.365 & 5.094 & $5.229 \mathrm{bc}$ \\
\hline 17 & $1.750 \mathrm{~cd}$ & $1.267 \mathrm{a}-\mathrm{c}$ & 1.509 & 5.417 & 4.347 & $4.882 \mathrm{c}$ \\
\hline IAC-1001 & $3.391 \mathrm{a}$ & $1.677 \mathrm{a}$ & 2.534 & 6.922 & 5.705 & $6.313 \mathrm{ab}$ \\
\hline IAC-1002 & $2.667 \mathrm{~b}$ & $1.517 \mathrm{ab}$ & 2.092 & 7.255 & 5.194 & $6.225 \mathrm{ab}$ \\
\hline IAC-1003 & $3.422 \mathrm{a}$ & $1.528 \mathrm{ab}$ & 2.475 & 7.172 & 6.139 & $6.655 \mathrm{a}$ \\
\hline F (Repetições) & 2,24 & 0,40 & - & 1,01 & $3,31 *$ & - \\
\hline F (Genótipos) & $19,39 *$ & $2,70 *$ & 1,97 & $4,57 *$ & $3,16^{*}$ & $4,60 *$ \\
\hline F (Anos) & - & - & $24,22 *$ & - & - & $58,14^{*}$ \\
\hline$F(G \times A)$ & - & - & $8,21 *$ & - & - & 1,38 \\
\hline d.m.s. (Tukey 5\%) & 711 & 597 & 1.474 & 1.510 & 1.193 & 1.264 \\
\hline C.V. $(\%)$ & 14,21 & 16,92 & 15,57 & 9,86 & 8,93 & 9,70 \\
\hline
\end{tabular}

*Significativo ao nível de 5\%. Médias seguidas de uma mesma letra em comum não diferem, entre si, pelo teste de Tukey.

de grãos. A cultivar IAC-1003 destacou-se pelo alto potencial produtivo exibindo nessas condições, média de $6.655 \mathrm{~kg} \mathrm{ha}^{-1}$, não diferindo apenas das linhagens $1,2,3,4,6,8$, 9 e das cultivares IAC-1001 e IAC-1002, com produção média variando de 5.392 a $6.313 \mathrm{~kg}$ ha-1. Genótipos de trigo duro com elevado potencial produtivo em condição de irrigação por aspersão e solo corrigido também foram identificados por CAMARGO et al. (1995a) e FeLício et al. (2005) avaliando genótipos em diferentes regiões paulistas.

Com a produção média de grãos obtida em Mococa, verificou-se a existência de grande potencial no melhoramento de trigo duro para esse caráter. Mesmo sem ter sido realizadas seleções diretas para esse caráter, durante o período de melhoramento genético foram detectadas linhagens com produções de grãos elevadas variando de 5.392 a $5.610 \mathrm{~kg} \mathrm{ha}^{-1}$, não diferindo da cultivar IAC-1003 (6.655 $\left.\mathrm{kg} \mathrm{ha}^{-1}\right)$.

Os quadrados médios das análises de variância conjuntas para altura das plantas demonstraram significância para genótipos em Capão Bonito, para anos nos dois locais e para a interação genótipos $\mathrm{x}$ anos apenas em Mococa (Tabela 2).

Considerando a média dos dois anos em Capão Bonito, a linhagem 2 destacou-se quanto ao porte semianão mais baixo, com média de $57 \mathrm{~cm}$, diferindo apenas da linhagem 17 e das cultivares IAC-1001, IAC1002 e IAC-1003, com porte semianão mais alto e altura média variando de 66 a $81 \mathrm{~cm}$.

A altura das plantas em Mococa, no ano de 2007, variou de 65 a $82 \mathrm{~cm}$. A linhagem 13 de porte semianão mais baixo, não diferiu das linhagens 1 , 2, 6, 8, 9, 10, 14 e 16. A linhagem 17 e a cultivar IAC-1001 são, nessas condições, de porte semianão mais alto. Em 2008, a altura média variou de 71 a $81 \mathrm{~cm}$, e a linhagem 10 revelou porte semianão mais baixo, diferindo da linhagem $15 \mathrm{e}$ da cultivar IAC-1001.

As linhagens obtidas pelo programa de melhoramento do IAC, de modo geral, exibiram plantas 
Tabela 2. Altura média das plantas dos vinte genótipos de trigo duro avaliados em condições de sequeiro (Capão Bonito) e com irrigação por aspersão (Mococa), em 2007 e 2008

\begin{tabular}{|c|c|c|c|c|c|c|}
\hline \multirow{2}{*}{ Genótipos } & \multicolumn{3}{|c|}{ Capão Bonito } & \multicolumn{3}{|c|}{ Mococa } \\
\hline & 2007 & 2008 & Média & 2007 & 2008 & Média \\
\hline 1 & 59 & 63 & $61 \mathrm{de}$ & $67 \mathrm{hi}$ & $74 \mathrm{ab}$ & 70 \\
\hline 2 & 55 & 59 & $57 \mathrm{e}$ & 67 hi & $78 \mathrm{ab}$ & 72 \\
\hline 3 & 64 & 64 & $64 c-e$ & $72 \mathrm{c}-\mathrm{g}$ & $75 a b$ & 73 \\
\hline 4 & 61 & 66 & $64 \mathrm{c}-\mathrm{e}$ & $75 \mathrm{~b}-\mathrm{d}$ & $77 \mathrm{ab}$ & 76 \\
\hline 5 & 63 & 60 & $61 \mathrm{de}$ & 74 b-e & $73 a b$ & 73 \\
\hline 6 & 64 & 63 & $63 \mathrm{c}-\mathrm{e}$ & $69 \mathrm{f}-\mathrm{i}$ & $73 a b$ & 71 \\
\hline 7 & 61 & 66 & $64 c-e$ & $70 \mathrm{e}-\mathrm{h}$ & $77 \mathrm{ab}$ & 73 \\
\hline 8 & 60 & 61 & $61 \mathrm{de}$ & $68 \mathrm{~g}-\mathrm{i}$ & $76 \mathrm{ab}$ & 72 \\
\hline 9 & 56 & 59 & $58 \mathrm{de}$ & 67 hi & $76 a b$ & 71 \\
\hline 10 & 61 & 68 & $64 c-e$ & $68 \mathrm{~g}-\mathrm{i}$ & $71 \mathrm{~b}$ & 70 \\
\hline 11 & 58 & 65 & $61 \mathrm{de}$ & $71 \mathrm{~d}-\mathrm{h}$ & $73 a b$ & 72 \\
\hline 12 & 60 & 64 & $62 \mathrm{de}$ & $73 c-f$ & $73 \mathrm{ab}$ & 73 \\
\hline 13 & 59 & 60 & $59 \mathrm{de}$ & $65 \mathrm{i}$ & $76 \mathrm{ab}$ & 70 \\
\hline 14 & 58 & 61 & $59 \mathrm{de}$ & $68 \mathrm{~g}-\mathrm{i}$ & $74 a b$ & 71 \\
\hline 15 & 60 & 68 & $64 \mathrm{c}-\mathrm{e}$ & $73 \mathrm{c}-\mathrm{f}$ & $80 a$ & 76 \\
\hline 16 & 60 & 66 & $63 \mathrm{c}-\mathrm{e}$ & $68 \mathrm{~g}-\mathrm{i}$ & $78 \mathrm{ab}$ & 73 \\
\hline 17 & 65 & 68 & $66 \mathrm{~b}-\mathrm{d}$ & $78 \mathrm{ab}$ & $77 \mathrm{ab}$ & 77 \\
\hline IAC-1001 & 83 & 80 & $81 \mathrm{a}$ & $82 \mathrm{a}$ & $81 \mathrm{a}$ & 82 \\
\hline IAC-1002 & 68 & 75 & $71 \mathrm{bc}$ & 74 b-e & $77 \mathrm{ab}$ & 76 \\
\hline IAC-1003 & 73 & 73 & $73 \mathrm{ab}$ & $76 \mathrm{bc}$ & $76 \mathrm{ab}$ & 76 \\
\hline F (Repetições) & 0,71 & 0,93 & - & 1,72 & $3,39 *$ & - \\
\hline F (Genótipos) & $10,18^{*}$ & $4,76^{*}$ & $12,43 *$ & $24,60 *$ & $2,09 *$ & 2,03 \\
\hline F (Anos) & - & - & $18,25^{*}$ & - & - & $24,17 *$ \\
\hline$F(G \times A)$ & - & - & 1,02 & - & - & $4,01 *$ \\
\hline d.m.s. (Tukey 5\%) & 10 & 13 & 9 & 5 & 9 & 12 \\
\hline C.V. $(\%)$ & 6,27 & 7,72 & 7,04 & 2,49 & 4,63 & 3,97 \\
\hline
\end{tabular}

*Significativo ao nível de 5\%. Médias seguidas de uma mesma letra em comum não diferem, entre si, pelo teste de Tukey.

de porte semianão mais baixo em relação às cultivarescontrole. Avaliando linhagens de trigo comum obtidas pelo programa do IAC, MisTro et al. (2001) identificou genótipos de porte semianão mais baixo em relação a linhagens oriundas de introdução, concordando com os resultados do presente trabalho. Esses pesquisadores relataram ainda que genótipos de porte mais baixo são preferidos para cultivo com irrigação por aspersão e elevadas doses de nitrogênio, devido à menor suscetibilidade ao acamamento em relação às plantas mais altas.

Os quadrados médios das análises de variância conjuntas para o comprimento médio da espiga revelaram dados significativos para genótipos, anos e interação genótipos $\mathrm{x}$ anos nos dois locais, exceto para genótipos em Capão Bonito (Tabela 3). Pelos resultados, constatouse que, para esse caráter, em cada local, houve diferenças no comportamento dos genótipos em função dos anos.

Em 2007, destacou-se quanto ao comprimento da espiga a cultivar IAC-1001 $(6,5 \mathrm{~cm})$, não diferindo apenas das linhagens 4, 10, 17 e da cultivar IAC-1003
(6,0 a 6,1 cm) em Capão Bonito. Nesse mesmo local, em 2008, a linhagem 15 exibiu espigas mais compridas $(6,0$ $\mathrm{cm})$, diferindo das cultivares IAC-1001, IAC-1002 e IAC$1003(4,9$ e $5,4 \mathrm{~cm})$.

No ensaio instalado em Mococa, em 2007, destacou-se a cultivar IAC-1001, com comprimento médio das espigas de $6,4 \mathrm{~cm}$, diferindo das linhagens $1,2,6,8,9,11,12,13,14,16$ e da cultivar IAC-1002, que exibiram comprimento médio de 5,3 a $5,8 \mathrm{~cm}$. Em 2008, as linhagens $1,3,4,7,15$, 16 e 17 demonstraram maior comprimento médio da espiga $(6,7$ a $6,9 \mathrm{~cm})$, diferindo apenas da cultivar IAC-1002 $(5,9 \mathrm{~cm})$. Grande variabilidade genética quanto ao comprimento da espiga também foi demonstrada por CAMARGo et al. (1995b). Entretanto, esses autores constataram que os genótipos de trigo duro tinham espigas mais curtas em relação às cultivares de trigo comum, avaliadas nas mesmas condições.

Os quadrados médios das análises de variância conjuntas do número médio de grãos por espiga 
Tabela 3. Comprimento médio das espigas dos vinte genótipos de trigo duro avaliados em condições de sequeiro (Capão Bonito) e com irrigação por aspersão (Mococa), em 2007 e 2008

\begin{tabular}{|c|c|c|c|c|c|c|}
\hline \multirow{2}{*}{ Genótipos } & \multicolumn{3}{|c|}{ Capão Bonito } & \multicolumn{3}{|c|}{ Mococa } \\
\hline & 2007 & 2008 & Média & 2007 & 2008 & Média \\
\hline 1 & $5,7 \mathrm{bc}$ & $5,6 \mathrm{ab}$ & 5,7 & $5,8 \mathrm{~b}-\mathrm{f}$ & $6,7 \mathrm{a}$ & 6,3 \\
\hline 2 & $5,6 \mathrm{bc}$ & $5,6 a b$ & 5,6 & 5,5 ef & $6,3 a b$ & 5,9 \\
\hline 3 & $5,9 \mathrm{bc}$ & $5,6 a b$ & 5,7 & 5,9 a-e & $6,9 \mathrm{a}$ & 6,4 \\
\hline 4 & $6,1 \mathrm{ab}$ & $5,9 \mathrm{ab}$ & 6,0 & $6,3 \mathrm{ab}$ & $6,8 \mathrm{a}$ & 6,6 \\
\hline 5 & $5,8 \mathrm{bc}$ & $5,6 a b$ & 5,7 & 5,9 a-e & $6,4 a b$ & 6,2 \\
\hline 6 & $5,8 \mathrm{bc}$ & $5,6 a b$ & 5,7 & $5,7 \mathrm{c}-\mathrm{f}$ & $6,4 a b$ & 6,0 \\
\hline 7 & $5,7 \mathrm{bc}$ & $5,7 \mathrm{ab}$ & 5,7 & 6,0 a-e & $6,7 \mathrm{a}$ & 6,4 \\
\hline 8 & $5,8 \mathrm{bc}$ & $5,6 a b$ & 5,7 & $5,6 \mathrm{~d}-\mathrm{f}$ & $6,4 a b$ & 6,0 \\
\hline 9 & $5,6 \mathrm{bc}$ & $5,8 \mathrm{ab}$ & 5,7 & 5,5 ef & $6,6 a b$ & 6,1 \\
\hline 10 & $6,0 \mathrm{a}-\mathrm{c}$ & $5,8 \mathrm{ab}$ & 5,9 & 5,9 a-e & $6,5 \mathrm{ab}$ & 6,2 \\
\hline 11 & $5,8 \mathrm{bc}$ & $5,5 \mathrm{ab}$ & 5,7 & $5,6 \mathrm{~d}-\mathrm{f}$ & $6,5 \mathrm{ab}$ & 6,0 \\
\hline 12 & $5,8 \mathrm{bc}$ & $5,8 \mathrm{ab}$ & 5,8 & $5,3 \mathrm{f}$ & $6,3 a b$ & 5,8 \\
\hline 13 & $5,8 \mathrm{bc}$ & $5,6 a b$ & 5,7 & $5,7 \mathrm{c}-\mathrm{f}$ & $6,1 \mathrm{ab}$ & 5,9 \\
\hline 14 & $5,5 \mathrm{c}$ & $5,6 \mathrm{ab}$ & 5,6 & $5,7 \mathrm{c}-\mathrm{f}$ & $6,4 \mathrm{ab}$ & 6,1 \\
\hline 15 & $5,9 \mathrm{bc}$ & $6,0 \mathrm{a}$ & 6,0 & $6,2 \mathrm{a}-\mathrm{c}$ & $6,9 \mathrm{a}$ & 6,5 \\
\hline 16 & $5,7 \mathrm{bc}$ & $5,6 a b$ & 5,7 & $5,6 \mathrm{~d}-\mathrm{f}$ & $6,7 \mathrm{a}$ & 6,1 \\
\hline 17 & $6,0 \mathrm{a}-\mathrm{c}$ & $5,7 \mathrm{ab}$ & 5,9 & 6,1 a-d & $6,9 \mathrm{a}$ & 6,5 \\
\hline IAC-1001 & $6,5 \mathrm{a}$ & $5,4 \mathrm{bc}$ & 6,0 & $6,4 \mathrm{a}$ & $6,6 a b$ & 6,5 \\
\hline IAC-1002 & $5,7 \mathrm{bc}$ & $4,9 \mathrm{c}$ & 5,3 & $5,6 \mathrm{~d}-\mathrm{f}$ & $5,9 \mathrm{~b}$ & 5,8 \\
\hline IAC-1003 & $6,0 \mathrm{a}-\mathrm{c}$ & $5,4 \mathrm{bc}$ & 5,7 & $6,1 \mathrm{a}-\mathrm{d}$ & $6,6 \mathrm{ab}$ & 6,4 \\
\hline F (Repetições) & 0,20 & 0,22 & - & 0,42 & 1,30 & - \\
\hline F (Genótipos) & $3,82 *$ & $3,83 *$ & 1,05 & $8,06^{*}$ & $2,90 *$ & $3,41 *$ \\
\hline $\mathrm{F}($ Anos $)$ & - & - & $10,03 *$ & - & - & $138,99 *$ \\
\hline $\mathrm{F}(\mathrm{G} \times \mathrm{A})$ & - & - & $3,90 *$ & - & - & $2,05^{*}$ \\
\hline d.m.s. (Tukey 5\%) & 0,6 & 0,6 & 0,9 & 0,6 & 0,8 & 0,8 \\
\hline C.V. $(\%)$ & 3,76 & 4,11 & 3,85 & 3,60 & 4,73 & 4,27 \\
\hline
\end{tabular}

*Significativo ao nível de 5\%. Médias seguidas de uma mesma letra em comum não diferem, entre si, pelo teste de Tukey.

demonstraram significância para genótipos, anos e interação genótipos $x$ anos, exceto para anos em Capão Bonito (Tabela 4).

A cultivar IAC-1001 destacou-se quanto à fertilidade da espiga em Capão Bonito, em $2007(44,9)$, não diferindo apenas da cultivar IAC-1002 $(43,0)$. Em 2008, a cultivar IAC-1002 exibiu espigas mais férteis, com média de 38,6, não diferindo apenas da linhagem 8 e das cultivares IAC-1001 e IAC-1003, com número médio de grãos por espiga variando de 32,5 a 34,3.

Apesar de se observar comportamento diferenciado dos genótipos em 2007 e 2008, a cultivar IAC-1002 proporcionou maior fertilidade da espiga em Mococa, com médias de 51,6 e 52,4 respectivamente, diferindo das demais linhagens, exceto da cultivar IAC1001, em 2007, com média de 48,8 e da linhagem 12 e das cultivares IAC-1001 e IAC-1003 em 2008, com médias variando de 44,6 a 50,3.

Pelas análises de variância conjuntas para massa de cem grãos constataram-se efeitos significativos para genótipos e anos, nos dois locais e para interação genótipos x anos apenas em Capão Bonito (Tabela 5).

Em Capão Bonito, no ano agrícola de 2007, destacaram-se as cultivares IAC-1002 e IAC-1003 quanto à massa de cem grãos $(5,22$ e 5,26 g), não diferindo das linhagens 1, 3, 5, 6, 15 e 17, com médias de 4,66 a 4,92 g. Em 2008, as linhagens 1, 15, 17 e a cultivar-controle IAC1003 com grãos mais pesados $(4,72$ a $4,78 \mathrm{~g})$, diferiram das linhagens $2,7,8,9,12,14$ e 16, com massa média de cem grãos variando de 3,84 a 3,98 g.

Em Mococa, considerando os dados médios obtidos nos dois anos, a massa de cem grãos variou de 4,35 a $5,47 \mathrm{~g}$. A cultivar IAC-1003 destacou-se quanto aos grãos mais pesados em relação às demais, não diferindo apenas das linhagens 15, 17 e da cultivar IAC-1002, com massa de cem grãos variando de 5,02 a 5,16 g.

Genótipos de trigo duro (CAMArgo et al., 1995b) e comum (BIUDEs et al., 2007) introduzidos do México, com alto potencial produtivo em solos corrigidos e com irrigação por aspersão e superioridade quanto ao 
Tabela 4. Número médio de grãos por espiga dos vinte genótipos de trigo duro avaliados em condições de sequeiro (Capão Bonito) e com irrigação por aspersão (Mococa), em 2007 e 2008

\begin{tabular}{|c|c|c|c|c|c|c|}
\hline \multirow{2}{*}{ Genótipos } & \multicolumn{3}{|c|}{ Capão Bonito } & \multicolumn{3}{|c|}{ Mococa } \\
\hline & 2007 & 2008 & Média & 2007 & 2008 & Média \\
\hline & & & & & & \\
\hline 1 & $23,8 \mathrm{f}$ & $21,1 \mathrm{~g}$ & 22,5 & $31,8 \mathrm{c}$ & $36,3 \mathrm{~d}$ & 34,1 \\
\hline 2 & $29,5 \mathrm{c}-\mathrm{e}$ & 30,8 b-f & 30,1 & $32,6 \mathrm{c}$ & $43,0 \mathrm{~b}-\mathrm{d}$ & 37,8 \\
\hline 3 & $27,3 \mathrm{c}-\mathrm{f}$ & $24,4 \mathrm{fg}$ & 25,8 & $30,8 \mathrm{c}$ & $42,0 \mathrm{~b}-\mathrm{d}$ & 36,4 \\
\hline 4 & $27,1 \mathrm{c}-\mathrm{f}$ & $28,0 \mathrm{~b}-\mathrm{f}$ & 27,5 & $35,7 \mathrm{c}$ & $42,6 b-d$ & 39,1 \\
\hline 5 & $26,5 \mathrm{c}-\mathrm{f}$ & $24,9 \mathrm{e}-\mathrm{g}$ & 25,7 & $33,0 \mathrm{c}$ & $38,6 \mathrm{~d}$ & 35,8 \\
\hline 6 & 24,6 ef & $26,0 \mathrm{c}-\mathrm{g}$ & 25,3 & $31,3 \mathrm{c}$ & $40,4 \mathrm{~d}$ & 35,8 \\
\hline 7 & $26,5 \mathrm{c}-\mathrm{f}$ & 29,0 b-f & 27,7 & $33,7 \mathrm{c}$ & $42,7 \mathrm{~b}-\mathrm{d}$ & 38,2 \\
\hline 8 & $30,1 \mathrm{c}-\mathrm{e}$ & $32,7 \mathrm{a}-\mathrm{c}$ & 31,4 & $33,3 \mathrm{c}$ & $40,7 \mathrm{~cd}$ & 37,0 \\
\hline 9 & $27,9 \mathrm{c}-\mathrm{f}$ & $31,5 \mathrm{~b}-\mathrm{e}$ & 29,7 & $33,6 \mathrm{c}$ & $42,4 \mathrm{~b}-\mathrm{d}$ & 38,0 \\
\hline 10 & $28,2 \mathrm{c}-\mathrm{f}$ & $25,0 \mathrm{~d}-\mathrm{g}$ & 26,6 & $33,3 \mathrm{c}$ & $39,1 \mathrm{~d}$ & 36,2 \\
\hline 11 & $28,0 \mathrm{c}-\mathrm{f}$ & 29,0 b-f & 28,5 & $36,4 \mathrm{c}$ & $43,1 \mathrm{~b}-\mathrm{d}$ & 39,7 \\
\hline 12 & $29,8 \mathrm{c}-\mathrm{e}$ & $31,8 \mathrm{~b}-\mathrm{d}$ & 30,8 & $33,5 \mathrm{c}$ & 44,6 a-d & 39,1 \\
\hline 13 & $31,1 \mathrm{c}$ & $24,6 \mathrm{fg}$ & 27,8 & $34,1 \mathrm{c}$ & $38,6 \mathrm{~d}$ & 36,3 \\
\hline 14 & $26,5 \mathrm{c}-\mathrm{f}$ & $25,5 \mathrm{~d}-\mathrm{g}$ & 26,0 & $31,9 \mathrm{c}$ & $40,0 \mathrm{~d}$ & 36,0 \\
\hline 15 & $25,2 d-f$ & $24,3 \mathrm{fg}$ & 24,7 & $31,5 \mathrm{c}$ & $35,9 \mathrm{~d}$ & 33,7 \\
\hline 16 & $30,6 \mathrm{~cd}$ & $31,6 \mathrm{~b}-\mathrm{e}$ & 31,1 & $31,8 \mathrm{c}$ & $42,1 \mathrm{~b}-\mathrm{d}$ & 36,9 \\
\hline 17 & $25,1 \mathrm{~d}-\mathrm{f}$ & $20,5 \mathrm{~g}$ & 22,8 & $31,0 \mathrm{c}$ & $38,2 \mathrm{~d}$ & 34,6 \\
\hline IAC-1001 & $44,9 \mathrm{a}$ & $32,5 \mathrm{a}-\mathrm{c}$ & 38,7 & $48,8 \mathrm{ab}$ & $49,8 \mathrm{a}-\mathrm{c}$ & 49,3 \\
\hline IAC-1002 & $43,0 \mathrm{ab}$ & 38,6 a & 40,8 & $51,6 \mathrm{a}$ & $52,4 \mathrm{a}$ & 52,0 \\
\hline IAC-1003 & $37,6 \mathrm{~b}$ & $34,3 \mathrm{ab}$ & 35,9 & $44,1 \mathrm{~b}$ & $50,3 \mathrm{ab}$ & 47,2 \\
\hline F (Repetições) & 0,48 & 0,77 & - & 0,33 & 0,20 & - \\
\hline F (Genótipos) & $27,97 *$ & $12,91^{*}$ & $6,50 *$ & $18,85^{*}$ & $6,41 *$ & $11,34 *$ \\
\hline $\mathrm{F}(\mathrm{Anos})$ & - & - & 2,60 & - & - & $109,44 *$ \\
\hline $\mathrm{F}(\mathrm{G} \times \mathrm{A})$ & - & - & $5,19 *$ & - & - & $1,87 *$ \\
\hline d.m.s. (Tukey 5\%) & 5,7 & 6,8 & 11,0 & 7,1 & 9,2 & 8,5 \\
\hline C.V. $(\%)$ & 7,33 & 9,17 & 8,19 & 7,73 & 8,31 & 7,96 \\
\hline
\end{tabular}

*Significativo ao nível de 5\%. Médias seguidas de uma mesma letra em comum não diferem, entre si, pelo teste de Tukey.

número de grãos por espiga e massa de cem grãos nessas condições, são fontes genéticas de interesse a serem utilizadas em cruzamentos ou mesmo apresentadas diretamente como nova cultivar.

Os quadrados médios das análises de variância conjuntas para comprimento do internódio da raque revelaram efeito significativo para genótipos apenas em Mococa, efeito de anos nos dois locais e não significativo para interação genótipos $\mathrm{x}$ anos, também somente em Mococa (Tabela 6).

As linhagens 1, 4, 15 e 17 possuem maior comprimento do internódio da raque em Capão Bonito, em 2007, com médias de 0,48 cm, diferindo das linhagens 5, 8, 9, 13, 16 e das cultivares IAC-1001, IAC1002 e IAC-1003, variando de 0,38 a 0,45 cm. Em 2008, as linhagens $1,4,15$ e a cultivar IAC-1001 com médias de $0,42 \mathrm{~cm}$, diferiram das linhagens $2,3,7,8,11,12,14,16 \mathrm{e}$ da cultivar IAC-1002, com médias de 0,37 a 0,39 cm.

Considerando a média dos dois anos em Mococa, o comprimento do internódio da raque variou de 0,36 a 0,43 $\mathrm{cm}$. A linhagem 17 foi superior quanto a esse caráter, exceto das linhagens 1, 4 e 15, que exibiram média de $0,42 \mathrm{~cm}$.

Avaliando genótipos de trigo comum FerReIRA FILHO (1996), também identificou genótipos com maior comprimento do internódio da raque. Por outro lado, esse autor demonstrou diferenças mais evidentes entre os genótipos avaliados em relação aos obtidos no presente estudo.

Os resultados demonstraram que houve uma tendência dos genótipos oriundos do programa de melhoramento do IAC, conter espigas menos compactas em relação a cultivar IAC-1002 introduzida do CIMMYT, México. Esse fato mostra o progresso já alcançado pelo programa de melhoramento de trigo duro do IAC em relação a esse caráter. Genótipos com maior comprimento do internódio da raque evitariam as perdas causadas pela germinação dos grãos na espiga antes da colheita.

As estimativas das correlações simples entre a produção de grãos e os caracteres agronômicos, obtidos 
Tabela 5. Massa média de cem grãos dos vinte genótipos de trigo duro avaliados em condições de sequeiro (Capão Bonito) e com irrigação por aspersão (Mococa), em 2007 e 2008

\begin{tabular}{|c|c|c|c|c|c|c|}
\hline \multirow{2}{*}{ Genótipos } & \multicolumn{3}{|c|}{ Capão Bonito } & \multicolumn{3}{|c|}{ Mococa } \\
\hline & 2007 & 2008 & Média & 2007 & 2008 & Média \\
\hline 1 & $4,82 \mathrm{a}-\mathrm{c}$ & $4,72 \mathrm{a}$ & 4,77 & 5,13 & 4,74 & $4,93 \mathrm{~b}-\mathrm{d}$ \\
\hline 2 & $4,33 \mathrm{~b}-\mathrm{d}$ & $3,98 \mathrm{~b}$ & 4,16 & 5,00 & 4,26 & $4,63 \mathrm{~b}-\mathrm{e}$ \\
\hline 3 & $4,80 \mathrm{a}-\mathrm{c}$ & $4,28 \mathrm{ab}$ & 4,54 & 5,20 & 4,39 & 4,79 b-e \\
\hline 4 & 4,46 b-d & $4,15 \mathrm{ab}$ & 4,31 & 4,84 & 4,54 & $4,69 \mathrm{~b}-\mathrm{e}$ \\
\hline 5 & $4,92 \mathrm{ab}$ & $4,28 \mathrm{ab}$ & 4,60 & 4,97 & 4,36 & $4,67 \mathrm{~b}-\mathrm{e}$ \\
\hline 6 & 4,66 a-d & $4,32 \mathrm{ab}$ & 4,49 & 4,84 & 4,33 & $4,58 \mathrm{c}-\mathrm{e}$ \\
\hline 7 & 4,46 b-d & $3,84 \mathrm{~b}$ & 4,15 & 4,72 & 4,31 & $4,51 \mathrm{de}$ \\
\hline 8 & $4,22 \mathrm{~cd}$ & $3,93 \mathrm{~b}$ & 4,07 & 5,09 & 4,41 & 4,75 b-e \\
\hline 9 & $4,37 \mathrm{~b}-\mathrm{d}$ & $3,92 \mathrm{~b}$ & 4,15 & 5,12 & 4,30 & $4,71 \mathrm{~b}-\mathrm{e}$ \\
\hline 10 & $4,55 \mathrm{~b}-\mathrm{d}$ & $4,15 \mathrm{ab}$ & 4,35 & 4,76 & 4,43 & $4,60 \mathrm{c}-\mathrm{e}$ \\
\hline 11 & $4,49 \mathrm{~b}-\mathrm{d}$ & $4,14 \mathrm{ab}$ & 4,32 & 5,19 & 4,37 & $4,78 \mathrm{~b}-\mathrm{e}$ \\
\hline 12 & $4,50 \mathrm{~b}-\mathrm{d}$ & $3,93 \mathrm{~b}$ & 4,21 & 4,97 & 4,40 & $4,68 \mathrm{~b}-\mathrm{e}$ \\
\hline 13 & $4,09 \mathrm{~d}$ & $4,15 \mathrm{ab}$ & 4,12 & 5,10 & 4,49 & 4,79 b-e \\
\hline 14 & 4,36 b-d & $3,92 \mathrm{~b}$ & 4,14 & 4,55 & 4,15 & $4,35 \mathrm{e}$ \\
\hline 15 & $4,84 \mathrm{a}-\mathrm{c}$ & $4,72 \mathrm{a}$ & 4,78 & 5,52 & 4,79 & $5,16 \mathrm{ab}$ \\
\hline 16 & $4,45 \mathrm{~b}-\mathrm{d}$ & $3,97 \mathrm{~b}$ & 4,21 & 5,15 & 4,31 & 4,73 b-e \\
\hline 17 & $4,75 \mathrm{a}-\mathrm{c}$ & $4,78 \mathrm{a}$ & 4,77 & 5,22 & 4,81 & 5,02 a-d \\
\hline IAC-1001 & $4,55 \mathrm{~b}-\mathrm{d}$ & $4,46 \mathrm{ab}$ & 4,50 & 5,02 & 4,66 & 4,84 b-e \\
\hline IAC-1002 & $5,22 \mathrm{a}$ & $4,21 \mathrm{ab}$ & 4,72 & 5,45 & 4,69 & $5,07 \mathrm{a}-\mathrm{c}$ \\
\hline IAC-1003 & $5,26 \mathrm{a}$ & $4,75 \mathrm{a}$ & 5,01 & 5,76 & 5,17 & $5,47 \mathrm{a}$ \\
\hline F (Repetições) & 2,58 & 0,25 & - & $6,31 *$ & 0,58 & - \\
\hline F (Genótipos) & $6,37 *$ & $6,32 *$ & $4,89 *$ & $6,15^{*}$ & $4,52 *$ & $7,17^{*}$ \\
\hline $\mathrm{F}($ Anos $)$ & - & - & $44,19 *$ & - & - & $199,04 *$ \\
\hline $\mathrm{F}(\mathrm{G} \times \mathrm{A})$ & - & - & $2,11^{*}$ & - & - & 1,16 \\
\hline d.m.s. (Tukey 5\%) & 0,64 & 0,64 & 0,73 & 0,60 & 0,61 & 0,53 \\
\hline C.V. $(\%)$ & 5,26 & 5,79 & 5,57 & 4,48 & 5,16 & 5,08 \\
\hline
\end{tabular}

*Significativo ao nível de 5\%. Médias seguidas de uma mesma letra em comum não diferem, entre si, pelo teste de Tukey.

nas 80 parcelas, dos vinte genótipos de trigo duro avaliados nos experimentos instalados em Capão Bonito, em condição de sequeiro e em Mococa, em condição de irrigação por aspersão estão apresentadas na tabela 7 . Considerando-se os dados médios dos dois anos de experimentação, verificou-se em Capão Bonito que houve uma tendência dos genótipos mais produtivos serem de porte semianão mais alto $\left(0,781^{*}\right)$, com maior número de grãos por espiga $\left(0,695^{\star}\right)$ e maior massa de cem grãos $\left(0,333^{*}\right)$. Em contrapartida, as plantas mais produtivas associaram-se com espigas mais compactas $\left(-0,354^{*}\right)$.

Considerando os dados médios obtidos em Mococa, observou-se que nos genótipos mais produtivos havia plantas de porte semianão mais alto $\left(0,404^{*}\right)$, espigas mais férteis $\left(0,710^{*}\right)$ e grãos mais pesados $\left(0,281^{*}\right)$.

Avaliando linhagens de trigo comum, BiUdes et al. (2007) também constataram que os genótipos mais produtivos tinham plantas de porte semianão mais alto. Associação positiva e significativa entre a produção de grãos e os caracteres número de grãos por espiga e peso de mil grãos também foram verificados na Espanha por ElHANI et al. (2007), avaliando linhagens de trigo duro em condição de sequeiro e irrigado, concordando com os dados obtidos no presente trabalho. Por outro lado, esses resultados discordaram parcialmente dos obtidos por Garcia Del Moral et al. (2005) em condição de sequeiro, cuja produção de grãos associou-se apenas ao número de grãos por espiga e ao número de espigas por área.

Na tabela 8, observa-se o comprimento médio das raízes dos vinte genótipos de trigo duro avaliados, além das cultivares-controle $\mathrm{BH}-1146$ (tolerante) e Anahuac (sensível), após 72 horas de crescimento em solução normal (sem alumínio), que se seguiu ao crescimento em solução tratamento, contendo seis diferentes concentrações de alumínio (média de quatro repetições). Verificou-se a diminuição do crescimento 
Tabela 6. Comprimento médio do internódio da raque dos vinte genótipos de trigo duro avaliados em condições de sequeiro (Capão Bonito) e com irrigação por aspersão (Mococa), em 2007 e 2008

\begin{tabular}{|c|c|c|c|c|c|c|}
\hline \multirow{2}{*}{ Genótipos } & \multicolumn{3}{|c|}{ Capão Bonito } & \multicolumn{3}{|c|}{ Mococa } \\
\hline & 2007 & 2008 & Média & 2007 & 2008 & Média \\
\hline 1 & $0,48 \mathrm{a}$ & $0,42 \mathrm{a}$ & 0,45 & 0,41 & 0,43 & $0,42 \mathrm{ab}$ \\
\hline 2 & $0,46 \mathrm{a}-\mathrm{c}$ & $0,39 \mathrm{~b}-\mathrm{d}$ & 0,42 & 0,38 & 0,40 & $0,39 \mathrm{de}$ \\
\hline 3 & $0,47 \mathrm{ab}$ & $0,39 \mathrm{~b}-\mathrm{d}$ & 0,43 & 0,40 & 0,41 & $0,41 \mathrm{bc}$ \\
\hline 4 & $0,48 \mathrm{a}$ & $0,42 \mathrm{a}$ & 0,45 & 0,40 & 0,44 & $0,42 \mathrm{ab}$ \\
\hline 5 & $0,45 \mathrm{~b}-\mathrm{d}$ & $0,40 \mathrm{a}-\mathrm{c}$ & 0,42 & 0,39 & 0,40 & $0,40 \mathrm{~cd}$ \\
\hline 6 & $0,46 \mathrm{a}-\mathrm{c}$ & $0,40 a-c$ & 0,43 & 0,39 & 0,41 & $0,40 \mathrm{~cd}$ \\
\hline 7 & $0,47 \mathrm{ab}$ & $0,39 \mathrm{~b}-\mathrm{d}$ & 0,43 & 0,40 & 0,41 & $0,40 \mathrm{~cd}$ \\
\hline 8 & $0,45 \mathrm{~b}-\mathrm{d}$ & $0,39 \mathrm{~b}-\mathrm{d}$ & 0,42 & 0,38 & 0,40 & $0,39 \mathrm{de}$ \\
\hline 9 & $0,44 \mathrm{c}-\mathrm{e}$ & $0,40 \mathrm{a}-\mathrm{c}$ & 0,42 & 0,39 & 0,41 & $0,40 \mathrm{~cd}$ \\
\hline 10 & $0,47 \mathrm{ab}$ & $0,40 \mathrm{a}-\mathrm{c}$ & 0,43 & 0,39 & 0,41 & $0,40 \mathrm{~cd}$ \\
\hline 11 & $0,47 \mathrm{ab}$ & $0,39 \mathrm{~b}-\mathrm{d}$ & 0,43 & 0,39 & 0,41 & $0,40 \mathrm{~cd}$ \\
\hline 12 & $0,47 \mathrm{ab}$ & $0,38 \mathrm{~cd}$ & 0,43 & 0,39 & 0,42 & $0,40 \mathrm{~cd}$ \\
\hline 13 & $0,43 \mathrm{de}$ & $0,40 \mathrm{a}-\mathrm{c}$ & 0,41 & 0,37 & 0,40 & $0,38 \mathrm{e}$ \\
\hline 14 & $0,46 \mathrm{a}-\mathrm{c}$ & $0,38 \mathrm{~cd}$ & 0,42 & 0,39 & 0,41 & $0,40 \mathrm{~cd}$ \\
\hline 15 & $0,48 \mathrm{a}$ & $0,42 \mathrm{a}$ & 0,45 & 0,41 & 0,44 & $0,42 \mathrm{ab}$ \\
\hline 16 & $0,45 \mathrm{~b}-\mathrm{d}$ & $0,39 \mathrm{~b}-\mathrm{d}$ & 0,42 & 0,38 & 0,42 & $0,40 \mathrm{~cd}$ \\
\hline 17 & $0,48 \mathrm{a}$ & $0,41 \mathrm{ab}$ & 0,44 & 0,41 & 0,45 & $0,43 \mathrm{a}$ \\
\hline IAC-1001 & $0,43 \mathrm{de}$ & $0,42 \mathrm{a}$ & 0,43 & 0,40 & 0,43 & $0,41 \mathrm{bc}$ \\
\hline IAC-1002 & $0,38 \mathrm{f}$ & $0,37 \mathrm{~d}$ & 0,37 & 0,35 & 0,37 & $0,36 \mathrm{f}$ \\
\hline IAC-1003 & $0,42 \mathrm{e}$ & $0,41 \mathrm{ab}$ & 0,42 & 0,39 & 0,42 & $0,40 \mathrm{~cd}$ \\
\hline F (Repetições) & 1,48 & 0,71 & - & 2,25 & 1,48 & - \\
\hline F (Genótipos) & $15,85^{*}$ & $5,39 *$ & 1,99 & $11,11^{*}$ & $5,03 *$ & $14,57 *$ \\
\hline F (Anos) & - & - & $117,44 *$ & - & - & $184,42 *$ \\
\hline $\mathrm{F}(\mathrm{G} \times \mathrm{A})$ & - & - & $7,21 *$ & - & - & 0,82 \\
\hline d.m.s. (Tukey 5\%) & 0,03 & 0,03 & 0,07 & 0,02 & 0,04 & 0,02 \\
\hline C.V. $(\%)$ & 2,75 & 3,01 & 2,88 & 2,10 & 3,41 & 2,92 \\
\hline
\end{tabular}

*Significativo ao nível de 5\%. Médias seguidas de uma mesma letra em comum não diferem, entre si, pelo teste de Tukey.

Tabela 7. Estimativas das correlações simples entre a produtividade e outros caracteres agronômicos, avaliados em condições de sequeiro (Capão Bonito) e condição de irrigação (Mococa), em 2007 e 2008

\begin{tabular}{lcc}
\hline Caracteres & Capão Bonito & Mococa \\
\hline Altura das plantas & $0,781^{*}$ & $0,404^{*}$ \\
Comprimento da espiga & 0,118 & 0,062 \\
Grãos por espiga & $0,695^{*}$ & $0,710^{*}$ \\
Peso de grãos & $0,333^{*}$ & $0,281^{*}$ \\
Comprimento do internódio da raque & $-0,354^{*}$ & $-0,191$ \\
\hline
\end{tabular}

* Significativo, ao nível de 5\%, pelo teste $\mathrm{t}$.

das raízes primárias centrais de todos os genótipos, à medida que aumentaram as concentrações de alumínio nas soluções.

Os genótipos obtidos pelo programa de melhoramento do IAC revelaram-se tolerantes às diferentes concentrações de alumínio (1 a $\left.6 \mathrm{mg} \mathrm{L}^{-1}\right)$. No entanto, as cultivares-controleIAC-1001,IAC-1002eIAC-
1003, originárias de introduções do CIMMYT, México, foram altamente sensíveis, pois exibiram a paralisação irreversível do meristema apical das raízes primárias centrais, em soluções contendo $1 \mathrm{mg} \mathrm{L}^{-1}$ de alumínio. Linhagens de trigo duro, oriundas de introduções do México, sensíveis ao alumínio em solução nutritiva, também foram identificadas por CAMARGO et al. (1992; 1993).

O fato de as linhagens mexicanas de trigo duro serem altamente sensíveis ao alumínio confirmou resultados obtidos por CAMARGO (1993). Esse autor revelou que uma das causas dessa sensibilidade seria a falta de pressão de seleção para tolerância ao alumínio no programa de melhoramento do CIMMYT, México, pois este se desenvolve em solos alcalinos de deserto, onde não há toxicidade de alumínio.

Os genótipos de trigo duro mais tolerantes ao alumínio poderiam ser utilizados como fontes genéticas desse caráter, em blocos de cruzamento, que poderão 
Tabela 8. Comprimento médio das raízes dos vinte genótipos de trigo duro em seis diferentes concentrações de alumínio (média de 4 repetições)

\begin{tabular}{|c|c|c|c|c|c|c|}
\hline \multirow{2}{*}{ Genótipos } & \multicolumn{6}{|c|}{ Concentração de alumínio $\left(\mathrm{mg} \mathrm{L}^{-1}\right)$} \\
\hline & 0 & 1 & 2 & 3 & 4 & 6 \\
\hline 1 & 84,3 & 60,2 & 39,9 & 29,1 & 15,3 & 5,5 \\
\hline 2 & 85,7 & 48,9 & 29,8 & 19,0 & 11,4 & 3,7 \\
\hline 3 & 82,2 & 58,7 & 41,3 & 26,3 & 16,1 & 6,7 \\
\hline 4 & 89,9 & 54,2 & 37,0 & 25,4 & 13,7 & 8,0 \\
\hline 5 & 89,1 & 55,5 & 36,0 & 25,2 & 13,7 & 5,4 \\
\hline 6 & 90,5 & 54,6 & 39,5 & 21,8 & 12,0 & 8,1 \\
\hline 7 & 91,1 & 60,9 & 43,5 & 29,5 & 16,7 & 5,8 \\
\hline 8 & 78,8 & 51,1 & 28,2 & 18,8 & 12,5 & 3,9 \\
\hline 9 & 82,6 & 52,2 & 30,6 & 16,9 & 8,0 & 3,3 \\
\hline 10 & 87,2 & 53,8 & 38,2 & 21,4 & 11,9 & 3,8 \\
\hline 11 & 80,5 & 50,7 & 34,0 & 18,3 & 13,6 & 3,7 \\
\hline 12 & 84,0 & 54,0 & 31,4 & 21,1 & 11,9 & 2,9 \\
\hline 13 & 78,0 & 56,2 & 38,1 & 26,1 & 18,4 & 4,7 \\
\hline 14 & 88,5 & 60,6 & 36,2 & 20,0 & 17,8 & 2,8 \\
\hline 15 & 84,2 & 55,4 & 39,6 & 22,4 & 13,6 & 8,0 \\
\hline 16 & 77,2 & 51,0 & 28,1 & 18,0 & 12,1 & 3,9 \\
\hline 17 & 92,2 & 58,8 & 34,7 & 20,5 & 14,6 & 5,2 \\
\hline IAC-1001 & 67,6 & 0,0 & 0,0 & 0,0 & 0,0 & 0,0 \\
\hline IAC-1002 & 87,4 & 0,0 & 0,0 & 0,0 & 0,0 & 0,0 \\
\hline IAC-1003 & 90,1 & 0,0 & 0,0 & 0,0 & 0,0 & 0,0 \\
\hline BH-1146 & 119,3 & 103,7 & 85,6 & 70,9 & 62,7 & 56,5 \\
\hline Anahuac & 92,6 & 2,8 & 0,0 & 0,0 & 0,0 & 0,0 \\
\hline
\end{tabular}

favorecer o crescimento e a expansão do cultivo desse cereal em solos, onde o alumínio se localiza naturalmente nas camadas mais profundas do solo, provocando perdas de produtividade pela toxicidade deste elemento.

\section{CONCLUSÕES}

1. As cultivares IAC-1001 e IAC-1003 destacamse quanto à produtividade de grãos em condição de sequeiro e irrigado, em solos corrigidos, além de serem fontes genéticas de interesse em cruzamentos para aumentar o número de grãos por espiga e massa de grãos respectivamente.

2. As linhagens 2, 9 e 13 de porte semianão mais baixo e as linhagens $1,4,15$ e 17 podem ser utilizadas como genitores para aumentar o comprimento do internódio da raque, em blocos de cruzamento.

3. Os genótipos mais produtivos são de porte semianão mais alto, espigas com maior número de grãos e grãos mais pesados.

4. As linhagens de trigo duro selecionadas pelo programa de melhoramento do IAC são tolerantes ao alumínio; as cultivares-controle oriundas de introduções do CIMMYT, México, são altamente sensíveis ao alumínio.

\section{AGRADECIMENTOS}

Ao Conselho Nacional de Desenvolvimento Científico e Tecnológico (CNPq) pela concessão de auxílio à pesquisa e de bolsa de produtividade e à Fundação de Amparo à Pesquisa do Estado de São Paulo (FAPESP), pela bolsa de mestrado.

\section{REFERÊNCIAS}

ABIMA. Associação Brasileira Industriais de Massas Alimentícias. Disponível em: http://www.abima.com.br/ est_mmundial.html. Acesso em 10 de outubro de 2008.

BIUDES, G.B.; CAMARGO, C.E.O.; FERREIRA-FILHO, A.W.P.; AZEVEDO-FILHO, J.A. Desempenho de genótipos de trigo introduzidos do México no Estado de São Paulo. Bragantia, v.66, p.403-411, 2007.

CAMARGO, C.E.O. Trigo. In: FURLANI, A.M.C. VIEGAS, G.P. (Ed.). O melhoramento de plantas no Instituto Agronômico. Campinas: Instituto Agronômico, 1993. cap.12, p.433-488.

CAMARGO, C.E.O.; CAMARGO, C.R.O.; FELÍCIO, J.C.; FERREIRA FILHO, A.W.P.; SANTOS, R.R..; DECOT, G. Avaliação das características agronômicas e tecnológicas de genótipos de trigo duro, trigo comum e triticale. Campinas: Instituto Agronômico, 1993. 28p. (Boletim Científico, 29) 
CAMARGO, C.E.O; FELÍCIO, J.C.; FERREIRA FILHO, A.W.P.; GALLO, P.B.; PETTINELLI JUNIOR, A.; SANTOS, R.R.; SABINO, J.C. Avaliação de linhagens da espécie Triticum durum L. no Estado de São Paulo. Bragantia, v.54, p.67-79, $1995 b$.

CAMARGO, C.E.O.; FELÍCIO, J.C.; FERREIRA FILHO, A.W.P.; LOBATO, M.T.V. Tolerância de genótipos de trigo comum, trigo duro e triticale à toxicidade de alumínio em soluções nutritivas. Bragantia, v.65, p.43-53, 2006.

CAMARGO, C.E.O.; FELÍCIO, J.C.; SANTOS, R.R.; FERREIRA FILHO, A.W.P. Trigo duro: Comportamento de genótipos no Estado de São Paulo. Bragantia, v.54, p.305-317, 1995a.

CAMARGO, C.E.O.; FERREIRA FILHO, A.W.P. Cultivo de trigo duro no Brasil. O Agronômico, v.52, p.13-18, 2000.

CAMARGO, C.E.O.; SANTOS, R.R.; PENTTINELLI JUNIOR, A. Trigo duro: tolerância à toxicidade do alumínio em solução nutritiva e no solo. Bragantia, v.51, p.69-76, 1992.

ELHANI, S.; MARTOS, V.; RHARRABTI, Y.; ROYO, C.; GARCIA DEL MORAL, L.F. Contribution of main stem and tillers to durum wheat (Triticum turgidum L. var. durum) grain yield and its components grown in Mediterranean environments. Field Crops Research, v.103, p.25-35, 2007.

FELÍCIO, J.C.; CAMARGO, C.E. de O.; ALVES PEREIRA, J.C.V.N.; BORTOLETTO, N.; GALLO, P.B.; FERREIRA FILHO, A.W.P. Adaptação, estabilidade e potencial produtivo de genótipos de Triticum durum L., irrigados por aspersão, no Estado de São Paulo. Bragantia, v.64, p.377-387, 2005.

FELÍCIO, J.C.; CAMARGO, C.E.O.; CASTRO, J.L.; GERMANI, R. Rendimento de grãos de trigo e sua relação com as doenças e variáveis climáticas em Capão Bonito de 1994 a 2001. Bragantia, v.63, p.93-103, 2004.

FELÍCIO, J.C.; CAMARGO, C.E.O.; MAGNO, C.P.S.; FREITAS, J.G.; BORTOLETTO, N.; PETTINELLI JUNIOR, A.; GALLO, P.B.; ALVES PEREIRA, J.C.V.N. Novos genótipos de Triticum durum L: rendimento, adaptabilidade e qualidade tecnológica. Bragantia, v.58, p.83-94, 1999.

FERREIRA FILHO, A.W.P. Estimativas de herdabilidades e dos coeficientes de correlações, entre características agronômicas, em populações híbridas de trigo. 1996. 68p. Dissertação (Doutorado) - Universidade Estadual Paulista, Jaboticabal.

GARCIA DEL MORAL, L.F.; RHARRABTI, ELHANI, E.; MARTOS, V.; ROYO, C. Yield Formation in Mediterranean durum wheats under two contrasting water regimes based on path-coefficient analysis. Euphytica, v.146, p.203-212, 2005.

GEBEYEHOU, G.; KNOTT, D.R.; BAKER, R.J. Relationships among durations of vegetative and grain filling phases, yield components, and grain yield in durum wheat cultivars. Crop Science, v.22, p.287-290, 1982.

INSTITUTO AGRONÔMICO (CAMPINAS). Recomendações da Comissão Técnica de Trigo para 2002. 2.ed.atual. Campinas, 2002. 92p. (Boletim Técnico IAC, 196)

LOBATO, M.T.V.; CAMARGO, C.E.O.; FERREIRA FILHO, A.W.P; BARROS, B.C.; PETTINELI JUNIOR, A.; PEREIRA. J.C.V.N.A.; GALLO, P.B. Desempenho de linhagens de trigo mexicanas, em condição de irrigação por aspersão no Estado de São Paulo. Arquivos do Instituto Biológico, v.72, p.211219, 2005

MEDEIROS, M.C.; SCHLEHUBER, A.M. Produção de grãos e componentes de produção de certa espécie de trigo. Pesquisa Agropecuária Brasileira, v.6, p.45-52, 1971.

MISTRO, J.C.; CAMARGO, C.E.O.; PETTINELLI JUNIOR, A. Avaliação de genótipos de trigo de diferentes origens, em relação à toxicidade de alumínio. Bragantia, v.60, p.177-184, 2001.

USDA. United State Department of Agriculture. Disponível em: http://www.backer vandsnacks.com/news/news/ aspid=64122. Acesso em 29 de outubro de 2008 . 